


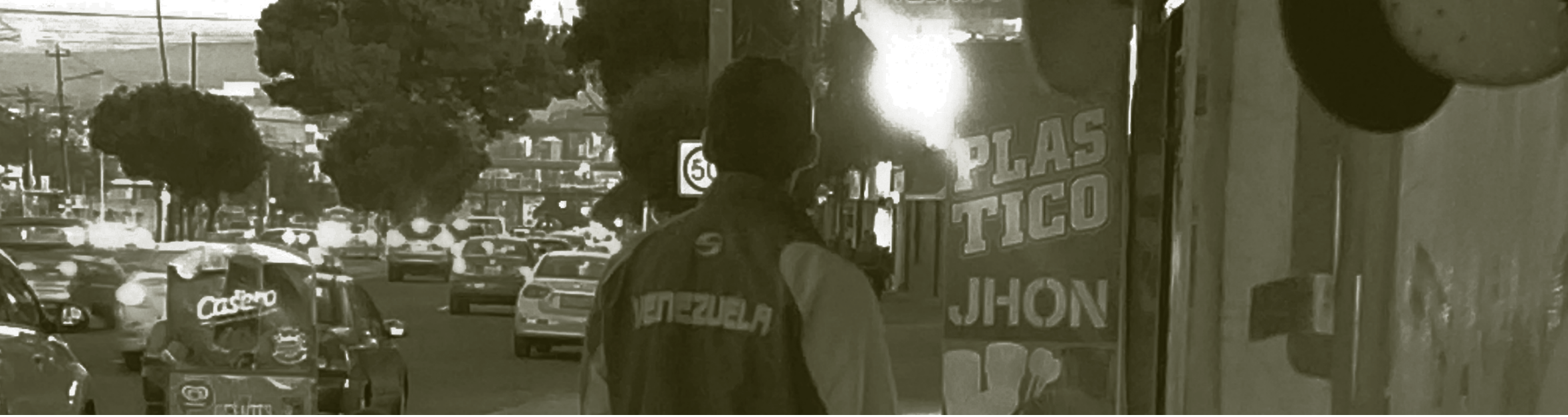

\section{LOCALIZACIÓN RESIDENCIAL INMIGRANTE EN EL MERCADO DE ALOUILER DEL DISTRITO METROPOLITANO DE QUITO}

Palabras clave: Localización residencial inmigrante, mercado residencial de alquiler, acceso a la vivienda, condiciones de habitabilidad, Distrito Metropolitano de Quito.

\section{Resumen}

Durante la última década Ecuador ha sido testigo del aumento de los flujos migratorios intra y extra continentales, lo que ha puesto en discusión las condiciones de inclusión económica e integración social de la población inmigrante. En este artículo se explora su acceso a la vivienda mediante una metodología cualitativa y socioespacial que aplica herramientas de observación, entrevista y cartografía para analizar los barrios de La Florida y La Floresta en el Distrito Metropolitano de Quito. El objetivo es exponer las lógicas diferenciadas que subyacen en los procesos de inserción, en cuanto a localización y habitabilidad, y analizar la existencia de fenómenos de segregación y autosegregación espacial y residencial en ambos barrios. El estudio reflexiona en torno al acceso a la vivienda inmigrante a partir de la relación existente entre el funcionamiento del mercado del suelo, de vivienda y alquiler y su relación con las condiciones socioeconómicas y migratorias de la población que habita estos espacios. Como resultado se expone el modo en que la presencia de población inmigrante configura la evolución territorial a nivel espacial, la composición poblacional en términos demográficos y las relaciones sociales desde una perspectiva concreta y simbólica. 


\section{Introducción y presentación del estudio}

La cifra de población inmigrante que optó por radicarse en Ecuador se triplicó en dos décadas, ubicándolo entre los cuatro países de inmigración media de la región (Sistema Continuo de Reportes sobre Migración Internacional en las Américas, 2015). Entre 2017 y 2019 la población inmigrante ascendió a 274.529, con un 68,6\% proveniente de Sudamérica (Instituto Nacional de Estadísticas y Censos [INEC], 2019), siendo Quito una de las principales ciudades de acogida para esta población.

Partiendo de la economía y la sociología urbana, se aborda la migración desde la perspectiva de su localización residencial, el acceso a la vivienda de alquiler y las condiciones de habitabilidad, para dar cuenta de experiencias diferenciadas en los barrios de La Florida y La Floresta, caracterizados por acoger a población inmigrante de características socioeconómicas y migratorias distintas entre sí.

El tema de estudio precisó la imbricación de tres esferas de análisis: Una económica-espacial, que permitió reflexionar sobre la localización residencial -partiendo del acceso al suelo como recurso y las condiciones bajo las cuales opera el mercado de la vivienda de alquiler- y pensar la inserción residencial inmigrante desde un plano territorial; una segunda esfera social, para examinar las características y condiciones inmigrantes que definen su acceso o restricción a la vivienda, así como las condiciones de habitabilidad y el nivel de apertura o rechazo en el espacio de acogida por parte de los habitantes autóctonos; y una esfera histórica, desde la cual se analizó la localización residencial inmigrante mediante la evolución de los territorios a través de su construcción histórica vinculada a procesos migratorios diferenciados, que permitieron indagar sobre el imaginario social en torno a la migración. 


\section{*.*vis revistainvi}

\section{Descripción de la problemática y estado del arte}

La literatura que aborda el tema de la localización residencial inmigrante (Arbaci, 2008; Arias et al., 2010; Fullaondo et al., 2013; Gómez y Sánchez, 2016; Kleidermacher, 2017; Murdie y Borgegard, 1998) permite inferir que existen características inherentes a la persona, relacionadas con categorías socioeconómicas y culturales, y determinantes extrínsecas definidas en el marco de una sociedad con prevalencia del capital -tales como el vínculo existente entre Estado y mercado de la vivienda, la existencia de regímenes urbanísticos de tenencia, y la estratificación socioeconómica urbana- que configuran una lógica que influye o determina su ubicación residencial.

Elementos como la nacionalidad y la clase social, ejes de identidad migrante como el estatus y el proyecto migratorio, conjuntamente con las redes de apoyo, se articulan con las condiciones de un territorio urbano configurado por una trama de poder que históricamente ha expresado la injusticia social a escala espacial a través de mecanismos estatales que, directa o indirectamente, legitiman procesos de normativa urbana y avalan operaciones inmobiliarias y crediticias que producen formas excluyentes y discriminatorias de ocupación del territorio y la vivienda.

En este contexto, el mercado del suelo define las lógicas del mercado de vivienda y del mercado residencial de alquiler configurando la distribución de la población en el territorio y el tipo de relaciones que en él se establecen (Abramo, 2010, 2012; Briceño León, 2008; Camagni, 2005; Contreras, 2016; Jaramillo, 2008; Parias, 2008). Bajo esta lógica se definirían dinámicas y prácticas habitacionales que inciden en las formas de habitar el territorio y de experimentar el derecho de acceso a la vivienda en base a una discusión entre elección y restricción.

La experiencia de la ubicación residencial inmigrante entonces puede ser pensada desde dos procesos probables: 1) la auto-segregación como consentimiento compartido de convivencia en base a vínculos culturales, étnicos y de redes de apoyo (Bolt et al., 1998; Musterd, 2011; Oliveira et al., 2016), y 2) la segregación o diferenciación en la localización espacial entre grupos poblacionales en base a una separación social fundamentada en lógicas capitalistas del mercado residencial y estrategias de exclusión basadas en el estigma (Bayona, 2007; Bolt et al., 2002, 2010; Colectivo IOE, 2004; Murdie y Borgegard, 1998; Musterd, 2010; Peach, 2010).

En este contexto, la auto-segregación puede ser concebida como una estrategia residencial, dentro del proceso migratorio, basada en la posibilidad de compartir lenguaje, cultura, identidad étnica y redes de apoyo, y como una práctica que ubica a los migrantes como protagonistas activos de su asentamiento (Logan et al., 2002; Mera, 2011; Pedreño, 1999; Portes y Zhou, 1996; Torres, 2009; Torres et al., 2007). 


\section{*.*vis revistainvi}

Pero también se puede concebir como un fenómeno fundamentado en la exclusión, mediante la imposición de ocupar espacios homogéneos en cuanto a condiciones territoriales, habitabilidad y componente poblacional, debido a que el mercado de la vivienda urbana está asentado en la segmentación racial y la separación de clase vinculada comúnmente con las nacionalidades de menor renta (Anderson, 1987; Colectivo IOE, 2004; Martínez del Olmo y Leal Maldonado, 2008; Sabatini, 2006). La auto-segregación configuraría entonces un espacio social uniforme mediante redes sociales que fortalecen y reproducen las relaciones de las cadenas migratorias, pero que a su vez dificultan las conexiones necesarias para un ascenso en términos socioeconómicos.

El tema de la segregación ha sido trabajado tanto en términos de las lógicas y dinámicas del mercado de suelo urbano (Echazarra, 2010; Fujita, 1989; García-Palomares, 2011; Sabatini y Brain, 2008; Schelling, 1978) como de las diferencias socioeconómicas y migratorias (Brenes Camacho, 2003; Domínguez et al., 2010; Marengo, 2004; Martori y Hoberg, 2006). La primera postura sostiene que la segregación es el resultado de la búsqueda de plusvalías y no de consolidación de fronteras entre grupos sociales (es decir, de diferencias de poder adquisitivo, no culturales), mientras que la segunda remite a las características de la población inmigrante (raza, etnia, idioma, nacionalidad, religión, etc.) como definitorias para la localización residencial en condición de segmentación (Galster et al., 1999; Massey y Denton, 1993; Musterd, 2010). No obstante, la segregación inmigrante facilita la apropiación y uso del espacio urbano, la conservación de las costumbres y el mantenimiento de la cohesión social (Noirel, 1988; Sassone et al., 2006; Simon, 1998).

\section{Metodología}

Se utilizó metodología mixta: cualitativa y de análisis socio-espacial. La primera permitió identificar como la localización de la vivienda articula las lógicas del mercado residencial, las características socio económicas y migratorias y el nivel de apertura de la sociedad receptora. La metodología de observación permitió examinar las características y condiciones de vida de los entrevistados inmigrantes en sus viviendas, el tipo de relación con la población autóctona al interior del barrio y el comportamiento de los agentes del mercado residencial de alquiler formal e informal con población autóctona e inmigrante.

Posteriormente, se aplicaron 34 entrevistas semi-estructuradas a población inmigrante (22) y nacional (12) bajo la técnica bola de nieve. En actores del negocio de alquiler de inmuebles, con el fin de indagar sobre las percepciones y supuestos de los arrendadores para con los arrendatarios inmigrantes al momento de rentar una propiedad; a la población autóctona del barrio, para conocer sus imaginarios sobre la cotidianidad en territorio, y a personas inmigrantes, con el objetivo de profundizar sobre las motivaciones, necesidades y condiciones que configuran la decisión o imposición de su localización residencial. 


\section{*.*vis revistainvi}

El perfil de arrendadores y arrendatarios entrevistados difiere principalmente por la pertenencia a una condición socioeconómica media baja y baja para la población de La Florida, donde los arrendatarios inmigrantes proceden en mayor medida de países del Sur Global, y media y media alta para los habitantes del barrio La Floresta, de arrendatarios inmigrantes que provienen mayoritariamente del denominado Norte Global.

El origen de la mayor parte de la población inmigrante entrevistada en La Florida es Colombia, Venezuela, Cuba, Chile, República Dominicana, Siria y Egipto, con un estrato socioeconómico medio bajo y bajo, y un solo caso de un inmigrante estadounidense de clase media; su cualificación laboral fue diversa pero todos ellos están dedicados actualmente al comercio y los servicios. En tanto, los entrevistados inmigrantes en La Floresta provienen mayormente de países como Canadá, Francia, España e Italia y, en menor medida, de México, Colombia y Venezuela, contando los primeros con un estrato socioeconómico más alto, una mejor cualificación laboral y mayores beneficios y estabilidad laboral que los segundos.

Entre los entrevistados nacionales estuvieron personas de condiciones étnicas, genéricas, etarias y cualificaciones laborales diversas, con el fin de obtener distintos puntos de vista sobre el mismo fenómeno. Finalmente, los arrendadores entrevistados pertenecieron a un mercado de alquiler informal para el caso del barrio de La Florida y formal e informal para el caso de La Floresta.

El trabajo cualitativo dio paso a la interpretación territorial de la localización residencial de los sujetos de estudio mediante el análisis socio-espacial, a través de la realización de cartografías adscritas a un mapeo a escala parroquial y urbana de la ubicación inmigrante en términos de vivienda.

\section{Resultados}

\section{BreVE REPASO DE LA PRESENCIA INMIGRANTE EN LOS BARRIOS}

El barrio constituye un espacio de coexistencia y reconocimiento de los individuos, un límite entre el espacio público, la ciudad, y el espacio privado, la vivienda. La Florida y La Floresta representan dos de los barrios de acogida y convivencia inmigrante más importantes en el Distrito Metropolitano de Quito, contando con características distintas entre sí respecto al mercado de alquiler y las condiciones de inserción residencial que ofrecen y, además, mostrando una diferenciación entre los estratos socioeconómicos por los que está compuesta su población, siendo La Florida un barrio conformado por un estatus socioeconómico inferior al de La Floresta. 


\section{粼 revistainvi}

Figura 1.

Pobreza por necesidades básicas insatisfechas en las Parroquias de La Concepción e Itchimbía.

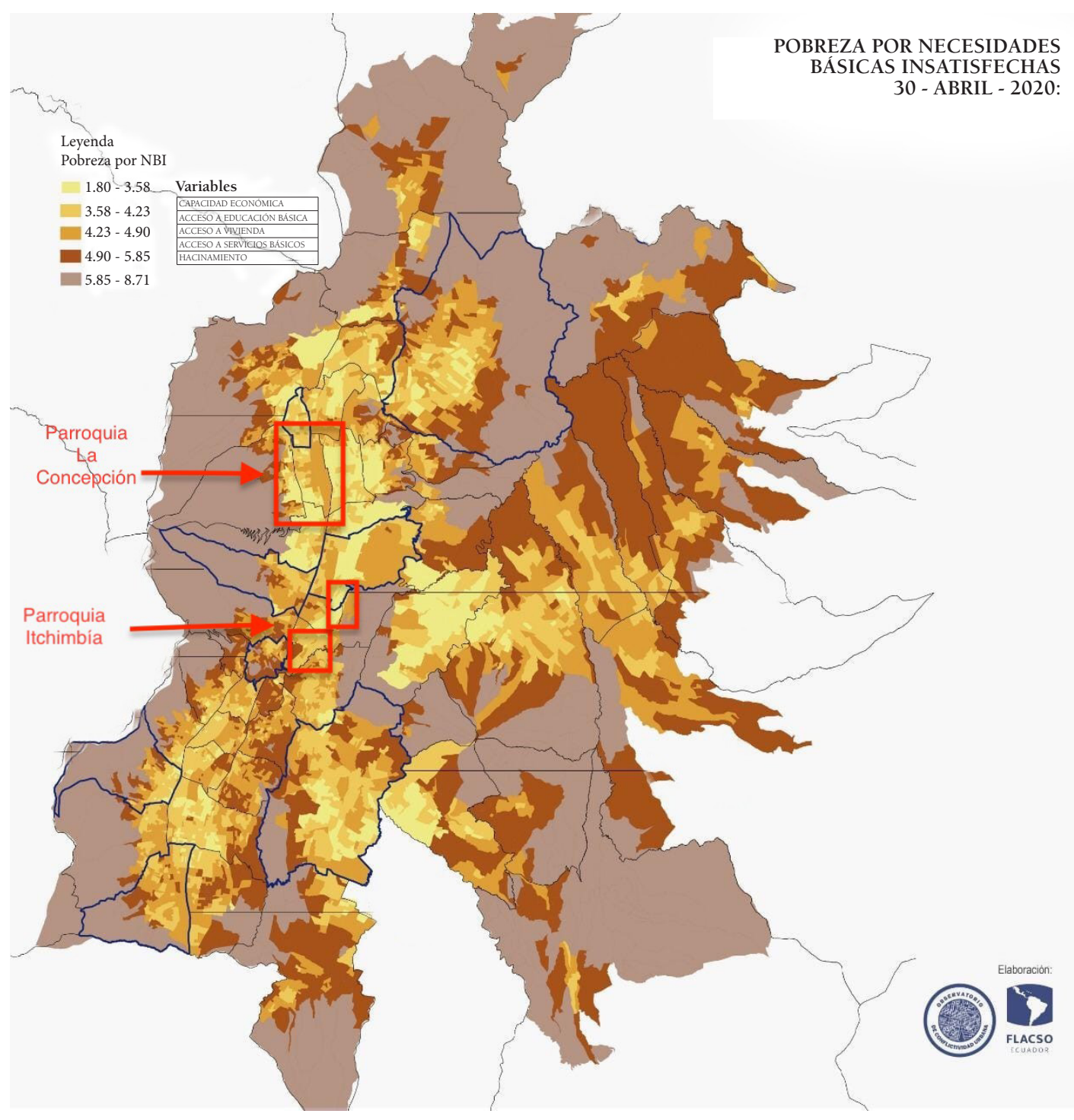

Fuente: INEC 2020 / Municipio del DMQ. Elaboración: FLACSO Ecuador. 
La Florida está ubicada al norte de la ciudad en la parroquia La Concepción, y fue constituida en 1964 sobre una hacienda de propiedad de militares jubilados de la Fuerza Aérea Ecuatoriana (FAE), y poblado en gran parte por sus familias que provenían de otras provincias del país, por lo que en sus inicios la composición poblacional fue de migrantes internos.

La presencia del aeropuerto internacional Mariscal Sucre fue también crucial y, a criterio de Rodríguez (2017), constituyó una causa para la concentración de residentes nacionales e inmigrantes en la zona, con un consecuente cambio en los patrones de crecimiento y conformación demográfica. A partir del 2008, con la promulgación de una nueva Constitución (calificada como de puertas abiertas) que reconocía a la población en movilidad como sujeto de derechos y que se considera dio paso al crecimiento en el flujo migratorio (Herrera et al., 2012), empiezan a llegar hasta La Florida ciudadanos cubanos, colombianos y haitianos.

Con el cierre del aeropuerto en 2013 se da paso a la construcción de edificios en altura y a la dinamización de espacios públicos que activan el barrio comercial y residencialmente. En este contexto, se consolida una tradición inmigrante con la llegada de población proveniente de países como República Dominicana, Chile, Siria, Egipto, y más recientemente, Venezuela.

La historia de La Floresta, ubicada en la parroquia Itchimbía al centro-norte de la ciudad, se remonta a la segunda década del siglo XX con la lotización de una hacienda privada, constituyéndose como un barrio icónico y tradicional al estar emplazado en un punto neurálgico en términos territoriales y simbólicos. En el contexto de un proceso de modernización -producto del boom petrolero de 1980- y de reconfiguración como resultado del proceso de globalización suscitado en 1990 (Carrión y Erazo, 2012), se inserta población proveniente de Norteamérica y Europa, algunos con un interés laboral y artístico. 


\section{revistainvi}

Figura 2.

Localización residencial de la población entrevistada en La Florida.

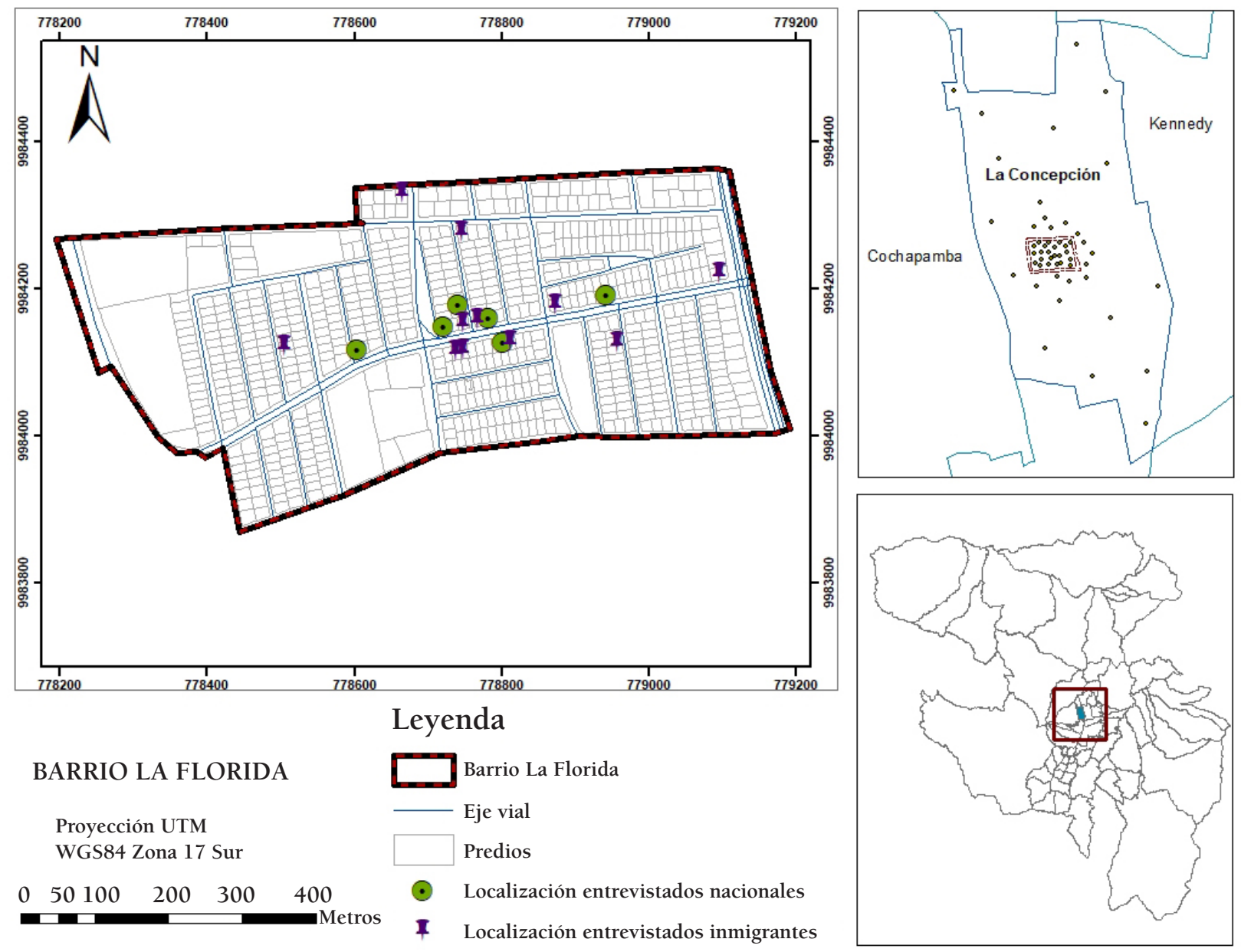

Fuente: Elaboración propia basado en Facultad Latinoamericana de Ciencias Sociales (Flacso), 2018. 


\section{粼 revistainvi}

Figura 3.

Población residente en La Florida.

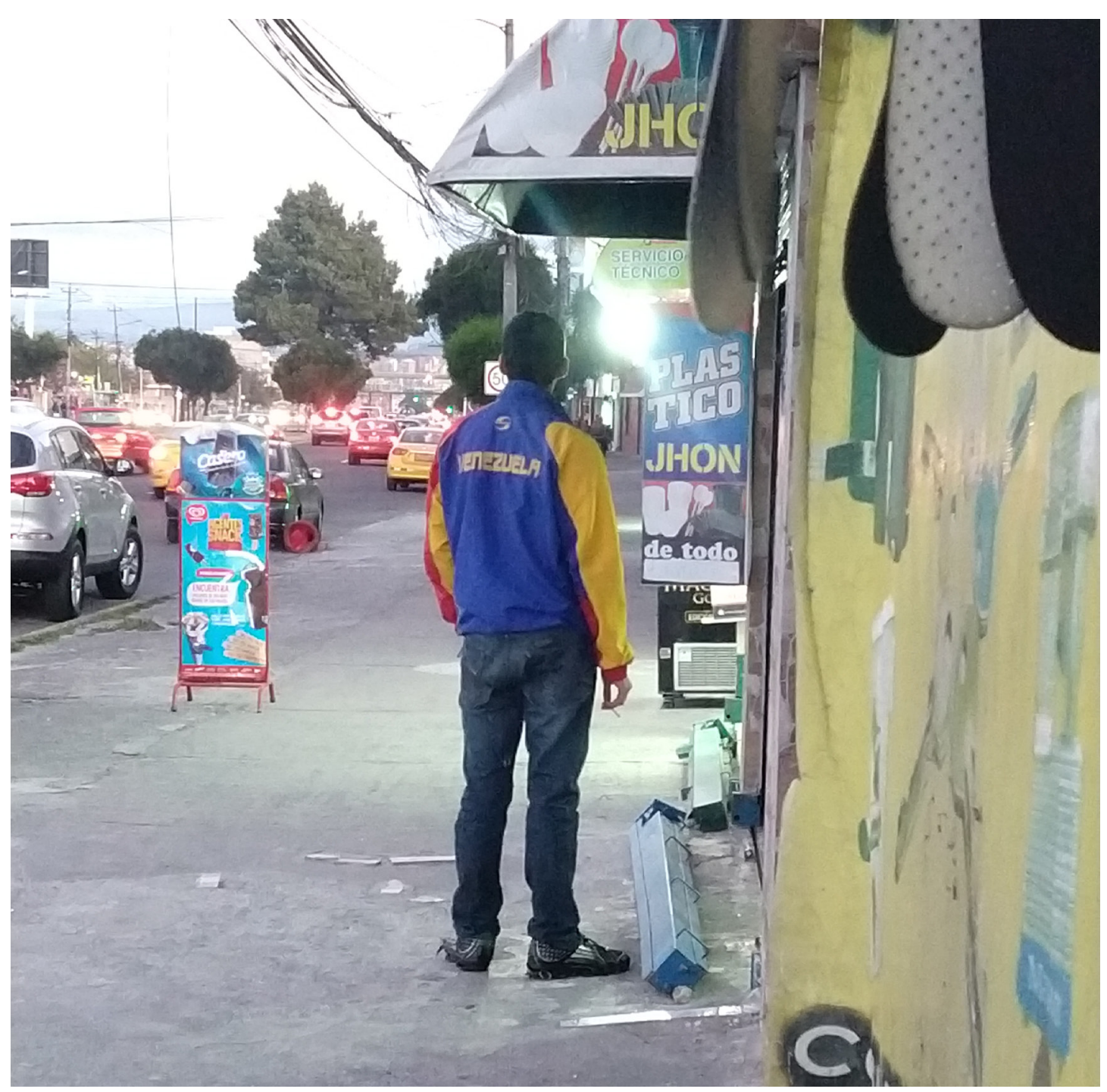

Foto de la autora. 


\section{粼 revistainvi}

Figura 4.

Localización residencial de la población entrevistada en La Floresta.

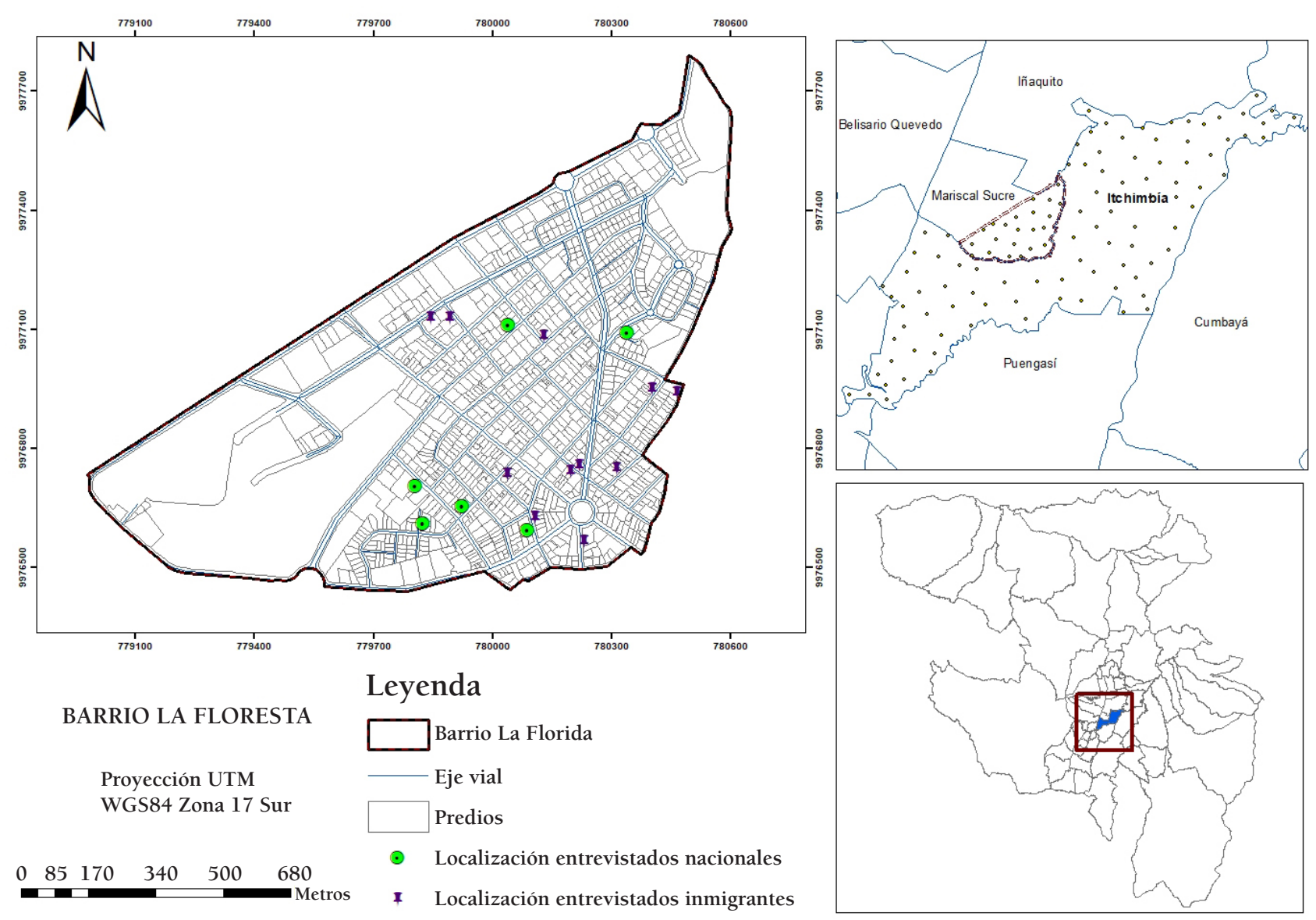

Fuente: Elaboración propia basado en Flacso, 2018. 


\section{粼 revistainvi}

Para el 2008 se suscribe el Plan Especial de Ordenamiento Urbano del Sector La Floresta. Este da lugar a la Ordenanza 135, un componente normativo que señala la localización según su función para los predios, así como su forma de ocupación y edificabilidad (Secretaría de Territorio, 2017), contribuyendo con la disolución de las antiguas fronteras espaciales del barrio.

Pero además propicia la entrada de un nuevo componente residencial y comercial de alquiler orientado a transacciones propias de un mercado de alta renta, y con ello al desplazamiento de grupos sociales de menores ingresos, la llegada de población nacional e inmigrante de ingresos altos, y la presencia de nuevas formas de economía y agencia que promueven las denominadas "nuevas clases creativas" (Florida, 2010).

No obstante, La Floresta acoge actualmente tanto a inmigrantes latinoamericanos de clases altas, que se hallan en capacidad de pagar por el alquiler de las viviendas, como a ciudadanos colombianos y venezolanos que se han instalado en viviendas de características precarias en las laderas y zonas periféricas del barrio. 


\section{粼 revistainvi}

Figura 5.

Desarrollo inmobiliario en La Floresta.

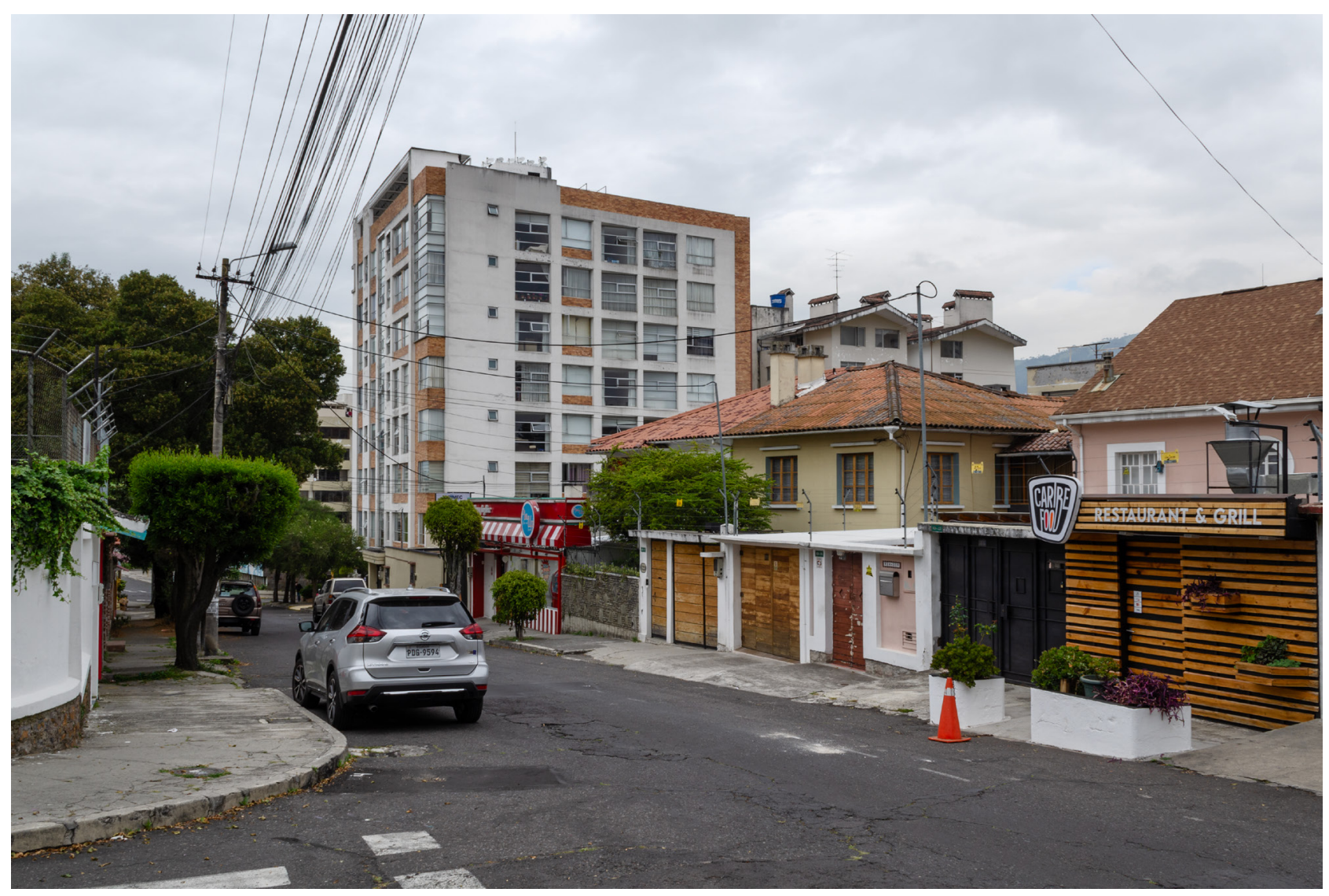

Foto de la autora. 


\section{*.*vis revistainvi}

\section{FunCIONAMIENTO DEL MERCAdO RESIDENCIAL DE ALOUILER}

En el contexto actual de producción neoliberal de ciudades, en el espacio urbano se reproducen relaciones sociales capitalistas y el mercado del suelo funge como mecanismo de coordinación de usos, estructuración y organización del territorio, disposición de dinámicas socio espaciales concretas y, a través de ello, composición socioeconómica de la población que se distribuye en la trama urbana. Fundamentados en lo que para Camagni (2005) constituyen los principios de organización ideal del espacio económico de las ciudades, los mercados del suelo propician la formación de desigualdades urbanas en el ámbito de la vivienda.

Bajo esta lógica, el emplazamiento de las actividades urbanas y los términos bajo los cuales opera el mercado de la vivienda de alquiler configuran el barrio como un espacio de diferenciación social en el ámbito territorial, el cual ofrece condiciones concretas en cuanto a ubicación y características de vivienda pero que también se constituye como un espacio simbólico que otorga prestigio o prejuicio a quien lo habita.

El impulso de las políticas públicas nacionales ha estado mayoritariamente direccionado a la producción y mejoramiento de la vivienda propia o la legalización de la vivienda informal, siendo el alquiler un asunto poco atendido pese a que constituye una solución práctica y viable a la demanda de vivienda para una amplia fracción poblacional, incluida la población inmigrante, para quienes representa la mejor opción en términos económicos y un proyecto migratorio que en la mayoría de casos es de residencia temporal.

En este escenario, la población en situación de movilidad se vincula con dos mercados de alquiler distintos. En La Floresta, un mercado formal y otro informal (a través de empresas inmobiliarias) y una oferta residencial producto de un naciente mercado vinculado al uso de plataformas web y redes sociales mediante redes migratorias que recomiendan opciones de renta y volantes informativos ubicados en el espacio público.

Existe una diferenciación entre las características de los inmuebles ofertados en este barrio, respecto a calidad en las condiciones de habitabilidad, y las características de la población en capacidad de acceder a ellos -en términos de clase social e incluso nacionalidad- debido a que en las decisiones de localización influye en gran medida el poder adquisitivo. Además de condiciones de acceso/restricción que operan simbólicamente, lo que contribuye a configurar un espacio de movilidad residencial relativamente preciso.

Al ser La Floresta un barrio de alta renta del suelo, bien conectado y con una oferta de comercios y servicios de alta gama, el precio de sus alquileres es proporcional a las condiciones que facilita, en una relación que según Camagni (2005) vincula el beneficio de vivir en una zona central con la capacidad económica de pagar por ella. Derivado del interés por habitar dicho espacio, surge un crecimiento en la oferta de alquiler mediante la inversión de grandes empresas inmobiliarias y la iniciativa de refacción y adecuación de antiguas casas y departamentos. 


\section{䊉 revistainvi}

Esta ampliación de la oferta inmobiliaria ha suscitado un cambio en el panorama urbano, mediante la presencia de empresas constructoras de gran escala y la demolición de casas antiguas para la construcción de edificios, lo que ha propiciado un incremento en los valores de alquiler junto con el aumento de la presencia de población extranjera de alta renta.

Para La Florida, los entrevistados accedieron a la vivienda a través de dos fuentes de carácter informal: redes migratorias y una oferta cuya información está disponible mediante volantes en negocios de alta afluencia inmigrante y el espacio público barrial. Habitada por población inmigrante cuyas decisiones de localización están en función de la conexión con sus redes, pero también determinadas por sus limitaciones económicas, esta población se ha acomodado al mercado de alquiler existente, lo que pone en evidencia que su localización residencial no sucede exclusivamente por elección.

\section{Figura 6:}

Oferta de alquiler informal en La Florida.

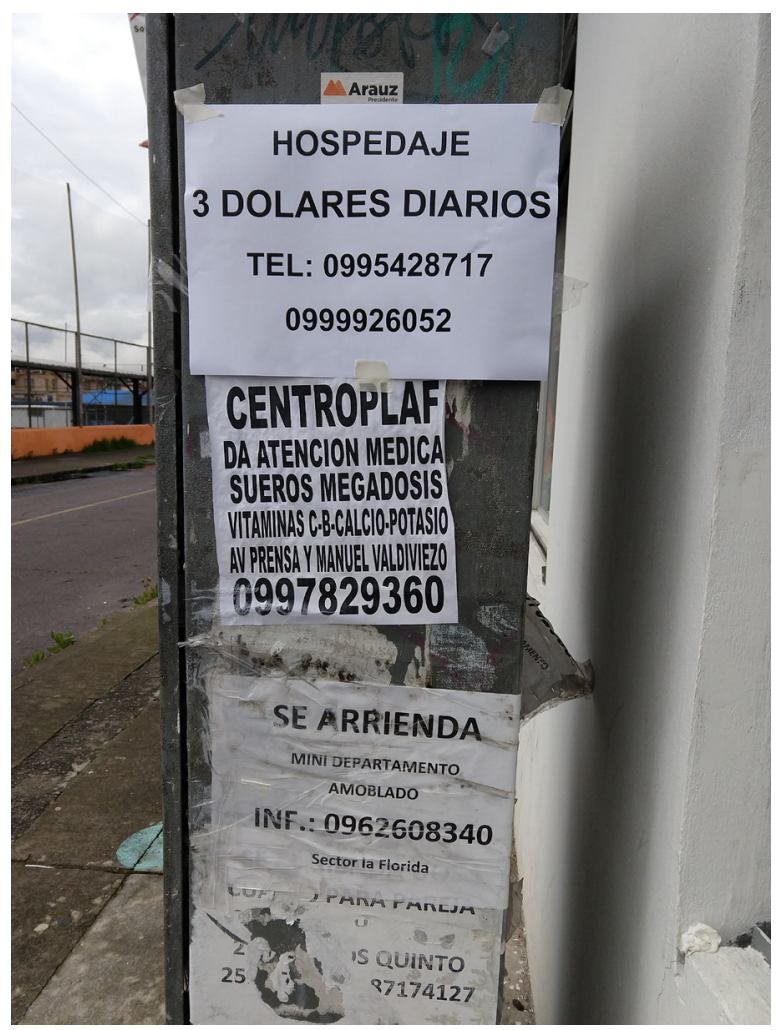

Foto de la autora. 


\section{*.*vis revistainvi}

La oferta residencial en La Florida incluye inmuebles refaccionados que no han sido creados con fines renteros, sino reacomodados en condiciones que no necesariamente resultan óptimas para albergar a población inmigrante que vive al día o con ingresos limitados. Se observaron departamentos con zonas de uso común que han sido modificadas como habitaciones, así como mini departamentos con habitantes que se han incrementado con el paso del tiempo. Por lo tanto, una fracción del mercado de alquiler en el que muchos inmigrantes se han insertado es en situación de hacinamiento y bajo condiciones mínimas de habitabilidad.

\section{Condiciones Socioespaciales de acceso a la Vivienda de ALQUiLER EN LOS BARRIOS}

"Norkis" (artesana, 58 años), venezolana con dos años de residencia en el barrio, habita el segundo piso de una antigua casa de La Florida. En la sala se observan colchones junto a maletas y cartones, y en la pared un horario de uso de los dos baños disponibles. En este espacio vive ella junto a su esposo, hijos, nietos, yerno, nuera y un par de sobrinos: "Somos como 14 personas en total, en la casa que tiene cuatro cuartos".

La segregación en este caso no estaría presente en términos de la localización en territorio, sino relacionada más bien con las características y condiciones de la vivienda, lo que da cuenta de la posición social de la población inmigrante a escala urbana. Se trataría en este caso de "un modelo de segregación social difusa" relacionado con régimen de tenencia, calidad de los inmuebles y condiciones de habitabilidad precarias (Colectivo IOE, 2004, p. 203).

Pensando esta localización residencial en clave de redes migratorias, Peach (2010) expone sobre la delgada línea existente en torno a los casos de elección de localización positiva, que pueden confundirse con discriminación negativa en los patrones de vivienda. Desde este enfoque, el concepto de enclave de Boal (1976), como una comunidad étnica segregada voluntariamente, de incrustación de Portes (1995), para denotar las relaciones recíprocas que forman una estrategia crucial de supervivencia entre personas que están cercanas social y geográficamente, y del capital étnico de Borjas (1998) permiten pensar a La Florida como un caso de autosegregación. Pero llegando a este punto resulta preciso retomar a Wacquant (1996), quien señala el riesgo de romantizar las condiciones de vida en los vecindarios proletarios y enclaves segregados.

En contraposición en La Floresta, el desarrollo inmobiliario experimentado es producto de una doble dinámica. En esta, la presencia inmigrante genera el crecimiento de la oferta tanto comercial como inmobiliaria y a su vez constituye un llamado para la población extranjera que busca ciertas condiciones en el espacio de residencia, lo que podría explicarse desde la búsqueda simbólica de un life style.

En este contexto, los mercados del suelo definen el acceso a la vivienda no solo en términos netamente económicos, sino también a través de su valor social respecto a otras zonas urbanas, una renta diferencial de 


\section{*.*vis revistainvi}

vivienda definida en función de condiciones específicas de los sujetos, donde las localizaciones "significan costos diferentes para apropiarse de valores de uso comparables" (Jaramillo, 2008, p. 167).

Entonces, la elección de un espacio de residencia también se produce a partir del acceso a un número de recursos localizados en el espacio urbano que constituyen una señal de posición social, que bajo la forma de un "impuesto privado", paga por la exclusividad de ocupar ciertos espacios, lo que Jaramillo (2008) conceptualiza como renta de segregación.

"Fabio" (actor, 46 años) italiano que reside en un amplio departamento refaccionado del centro de La Floresta, se refiere a una de las cafeterías más conocidas de su barrio:

"La Cleta no es del ecuatoriano, del indio que hay acá, la Cleta es de la modernidad. No sé si hay un barrio a nivel visual como la Floresta que me evoque al lugar de donde vengo, acá me siento más a gusto, me siento como en casa".

Pero el pago de este "impuesto" no está al alcance de todos los habitantes de La Floresta; de ahí que la segregación se manifieste en la ubicación periférica al interior del barrio y las condiciones de habitabilidad que experimentan inmigrantes provenientes de países del denominado Sur Global. La renta se constituye entonces como un motor depurador del tipo de población en capacidad de habitar un sector y un tipo de vivienda determinado, y en condición de modificar el mercado de alquiler, las prácticas cotidianas y los patrones de consumo. Así lo señala "Samuel", técnico electrónico ecuatoriano de 74 años y que vivió por 40 años en La Floresta: "Cuando vendieron me tuve que pasar a donde vivo ahora, aquí me hubiera gustado seguir, pero el factor económico me hizo salir, muy caro La Floresta. Ha subido bastantísimo, imposible de comprar para mucha gente de aquí".

Lo que podría pensarse como un incipiente proceso de gentrificación estaría caracterizado entonces por dos fenómenos: la expulsión de una fracción de habitantes tradicionales ante la imposibilidad de pagar el sobreprecio generado por una industria inmobiliaria en expansión y el ejercicio de presión sobre la población extranjera de recursos limitados a habitar espacios periféricos y/o viviendas en estado ruinoso o en condición de hacinamiento. De este modo, el prestigio, el estatus y las relaciones sociales que se establecen al interior del barrio territorializan la diferenciación social entre sus habitantes. Smolka (2005) considera que esta práctica diferenciadora en el ámbito residencial es una suerte de "blindaje social" que deriva en segregación residencial.

En este sentido, podríamos hablar tanto de la existencia de patrones de segregación impuesta, como de una auto-segregación elegida en ambos barrios. Tanto en La Florida como en La Floresta las limitaciones económicas de la población de determinadas nacionalidades dan lugar a la imposición de condiciones de habitabilidad precarias, no obstante, en el segundo barrio la segregación está también manifiesta en la localización en territorio. En tanto que la auto- segregación funcionaría en ambos casos sobre una facultad de elección en la localización residencial determinada para La Floresta por el poder económico de la población migrante y su búsqueda por convivir con gente de un estatus social similar y, para la Florida, por el interés de coincidir con redes migratorias. 


\section{*.*vis revistainvi}

No obstante, esta idea de una facultad de elección motivada por redes migratorias para el caso de La Florida, que constituirían el impulso para optar por residir en este barrio por encima de otros territorios con una renta de alquiler más baja o mejor ubicados, no deja de chocar con la existencia concreta de condiciones de habitabilidad precarias y patrones de exclusión socio residenciales que ponen en evidencia el alcance limitado de esta propuesta.

\section{Condiciones y CARACTERÍSTICAS dE LA POBLACIÓN INMIGRANTE E INSERCIÓN RESIDENCIAL}

Es posible establecer que el aspecto socioeconómico y la nacionalidad son las condiciones que en la población inmigrante tienen mayor peso para la determinación del acceso a una vivienda y el nivel de aceptación en ambos barrios. Aunque contar con recursos financieros puede aminorar la importancia de un origen estigmatizado socialmente, el dinero no asegura la inserción residencial si se trata de una nacionalidad en extremo desacreditada por prejuicios. Strohmayer et al., (2005) señalan el modo en que la nacionalidad se territorializa en el ámbito de la vivienda mediante una diferenciación en localización residencial y una segmentación derivada del sistema de representaciones que la sociedad receptora tiene sobre los inmigrantes de un origen $u$ otro.

En tanto, el tema del estatus migratorio tiene una importancia diferenciada para los barrios y está conectada tanto con el tiempo de llegada al país como con la capacidad económica inmigrante. En La Florida la posibilidad de regularización del estatus migratorio ha sido determinado en mayor medida en función del tiempo de llegada, que posibilitó a los inmigrantes más antiguos tramitar con mayor facilidad este requisito y con ello mejorar sus condiciones de acceso a la vivienda en el barrio.

Mientras, la población venezolana, protagonista de un proceso migratorio más reciente, se encuentra residiendo irregularmente en el país y experimenta complicaciones con los documentos necesarios para formalizar el proceso de alquiler, lo que deviene en una realidad socio habitacional más precaria. No es el caso de la mayoría de los habitantes inmigrantes de La Floresta, quienes han contado con el capital económico necesario para regularizar su estatus migratorio independientemente de su tiempo de llegada sin experimentar, por este asunto, restricciones en el acceso a condiciones residenciales óptimas.

En cuanto a las redes migratorias, "conjuntos de vínculos interpersonales que conectan a migrantes, antiguos migrantes y no migrantes en su área de origen y de destino a través de los lazos de parentesco, amistad y comunidad de origen compartida" (Massey et al., 1998, p. 4), en La Floresta se limitan a la provisión de información y acompañamiento en el proceso de instalación. Mientras que en La Florida tienen una importancia particular, al ser un territorio constituido en su mayoría por población foránea de recursos 


\section{*.*vis revistainvi}

económicos limitados, contribuyen a bajar los costes, elevar los beneficios y mitigar los riesgos del movimiento migratorio, por lo que pueden ser consideradas capital social, lo que puede ser pensado desde una condición de auto-segregación residencial.

La importancia de estas redes son también su contribución a la creación de una comunidad extranjera de fuertes raíces identitarias, por encima de barrios que ofrezcan mejores condiciones de inserción. Así lo sostienen los venezolanos "Alexis" y "Bryan": "Es que hay muchos migrantes que viven en La Florida (...), hay muchos, muchos. Que haya más gente migrante es... que no estoy solo, no estoy solo" ("Alexis", obrero, 42 años).

"Tenía un amigo que había vivido aquí y tenía algo de información sobre el barrio y el lugar, y acá estaba mi mamá, mi tía y mi primo (...). Me dijeron que había otras partes de la ciudad que estaba un poco más económico, pero pues, acá ya estaban ellos" ("Bryan”, barbero, 22 años).

La auto-segregación inmigrante fundamentada en redes según Bolt et al. (2002) no debe ser contrarrestada si es resultado de la elección positiva. Peach (2010) coincide al señalar que su existencia es importante para mantener la cohesión grupal a través de la concentración espacial. Del otro lado, Sabatini es enfático en apuntar que "la segregación de grupos raciales o étnicos discriminados tiende a coincidir espacialmente con la segregación de los grupos socioeconómicos bajos" (Sabatini, 2006, p. 5), lo que invalida la idea de existencia de una segregación positiva o elegida por encima de una impuesta.

\section{INSERCIÓN E INTEGRACIÓN RESIDENCIAL INMIGRANTE A LA LUZ DE LAS CONDICIONES SOCIALES Y MIGRATORIAS}

En La Florida la presencia inmigrante ha propiciado nuevas lógicas de interacción en el espacio público y un importante cambio en el funcionamiento del mercado residencial, comercial y de servicios, estos últimos mayoritariamente de propiedad de personas inmigrantes. "Raúl", comerciante ecuatoriano con 35 años de residencia en La Florida, cuenta sobre lo sucedido:

"Este era un barrio quieto, callado, medio conventual como la ciudad misma de Quito, pero con la llegada de población cubana, y más con los venezolanos, se convirtió en un barrio bullicioso, alegre, entretenido (...). La personalidad del barrio se ha vuelto más extrovertida, usted ve más movimiento en las calles, más interacción entre las personas".

La concentración residencial de la población inmigrada favorece una apropiación del espacio urbano que contribuye con la creación de negocios étnicos orientados a las necesidades de la población migrante, lo que Bolt et al. (1998) conciben como empresa orientada internamente. Estas dinámicas han traído consigo el impulso de un sentido de pertenencia más profundo respecto a un territorio que la población inmigrante 


\section{*.*vis revistainvi}

modifica e influye, generando vínculos y relaciones respecto al espacio vivido y forjándose un sentido de pertenencia y afecto, lo que desde la Escuela de Geografía Humanista, de manos de Yi Fu Tuan (2007), se conoce como topofilia.

Por el contrario, los espacios de encuentro y relación en La Floresta son de carácter privado y comúnmente financiados por un capital nacional o extranjero externo al barrio cuya función es utilitaria y está vinculada a preferencias e intereses relacionados con el arte y la cultura, pero no necesariamente ligados exclusivamente con necesidades particulares de la población inmigrante que lo habita.

Al establecer la relación existente entre las características de la población inmigrante y su localización residencial en ambos barrios, es posible sostener la existencia de condiciones que determinan el tipo de inserción y la experiencia por la que atraviesan. Para "Ibrahim" (músico, 46 años), egipcio dueño de un conocido restaurant y arrendatario de un departamento en La Florida, la capacidad socioeconómica marca, por sobre la nacionalidad, la experiencia en territorio:

"El trato es diferente en general porque los árabes tienen dinero y están trabajando en muchas cosas (...). Los prejuicios aquí son dos: de clase y nacionalidad. Puedes encontrar un venezolano de mucho dinero y van a tratarlo de otra manera (...). Importa la plata y echar la culpa por la nacionalidad"

En tanto para el cubano "Ernesto" (chef, 42 años), que habita una pequeña vivienda de dos habitaciones junto a su esposa y dos hijos, por encima de la solvencia económica pesan los prejuicios sobre nacionalidad: "En los otros barrios, por ejemplo, en barrios más pudientes, nos rechazaron realmente al principio (...), pues busqué otro lugar y ya, lo que nos dijeron fue que éramos cubanos". La imposibilidad de habitar ciertos espacios en igualdad de oportunidades da cuenta entonces del modo en que la ciudad se encuentra dividida por fronteras de tipo práctico y simbólico, siendo la xenofobia una manifestación concreta de rechazo que derivaría en segregación, todo lo contrario a la idea de una facultad de elección residencial.

Para la mayoría de entrevistados de La Florida, la tradición inmigrante del barrio ha facilitado que el comportamiento de la población local sea más abierto y amigable respecto a la presencia extranjera. Del otro lado se ubican quienes consideran que el barrio es igual o incluso más xenófobo que otros espacios de la urbe, siendo la presencia extranjera la que exacerba la antipatía y el rechazo.

Para "Ibrahim" (músico, 46 años), la xenofobia en La Florida es parte de una cultura de discriminación enraizada en la idiosincrasia de la población ecuatoriana, que funciona como un chivo expiatorio que varía a conveniencia y en función de la coyuntura,

"No pueden ser abiertamente [xenófobos] porque todos en el barrio viven de estos inmigrantes, entonces no van a decir "salgan de aquí" (...). Siempre están colgando cosas negativas al que viene. Si no están los inmigrantes, está el costeño, el mono, el negro, no sé qué”.

Por su parte, los actores del mercado inmobiliario mantienen prejuicios en torno a las condiciones de hacinamiento en las que habita una fracción de la población extranjera, mostrando resistencia ante la 


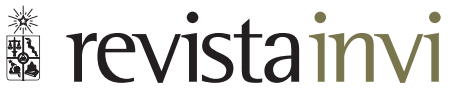

posibilidad de rentar sus inmuebles. Como "Román" (ingeniero, 56 años), heredero de una casa rentera de tres pisos en La Florida, disponible solo para población ecuatoriana:

"No ha sido beneficiosa la presencia de población extranjera en el barrio, al contrario, porque el rato que voy a arrendar ya no es una ciudadela de nivel alto, sino más bien una ciudadela de nivel bajo por lo que hay mucho migrante, de baja categoría se podría decir".

Este temor estaría relacionado con la preservación del valor de los inmuebles y su rentabilidad, razón por la cual Harvey y Chatterjee, (1974) consideran que la dinámica entre arrendador y arrendatario funciona como una relación entre productores y consumidores de vivienda a modo de clases en conflicto.

Por el contrario, para el caso de La Floresta la capacidad financiera de la población, sumada a lo que podría considerarse como discriminación positiva, ha facilitado una inserción residencial digna y un mejor nivel de aceptación y acogida en el barrio. Así lo considera "Charlotte" (periodista, 35 años), canadiense que habita un moderno loft usado como vivienda y espacio de trabajo: "Es complicado, yo que tengo piel blanca hace que la gente me trate mejor, yo soy como un símbolo de plata. O sea, no podemos ignorar eso, así que yo siento que nunca he tenido experiencias malas acá".

Bajo esta lógica, hay una diferencia clara entre las condiciones con las que puede acceder a una vivienda en renta una persona de origen anglosajón y otra latina, con una diferencia en la apertura y el trato que reciben por parte de la población nacional y los arrendadores. Lo reafirma "Ricardo" (técnico en sistemas, 53 años), ecuatoriano con 53 años de residencia en el barrio, quien, ante la pregunta sobre su percepción de la población inmigrante residente en La Floresta, responde: "Me pregunta específicamente isobre cuáles? ¿los latinos o los inmigrantes?".

En base a este criterio, de una distinción entre "migrantes de primera y segunda categoría", se observa también la existencia de fronteras concretas y simbólicas que determinan una localización residencial diferenciada. Mientras quienes provienen de una migración norte-sur se localizan en la centralidad de La Floresta, la población correspondiente a una migración sur-sur se ubica en las laderas y periferias del barrio, en una suerte de territorialización de la diferencia social.

Escaffre (2018) define estos espacios como periferias internas, territorios en condiciones de segregación ocupados por población que ha accedido al suelo y la vivienda en condiciones de centralidad, pero de características precarias. De allí que Echazarra (2010) haya establecido una diferenciación entre "segregación inferior", para la población inmigrante de menor renta que la nacional y que está ubicada residencialmente en espacios de menor calidad, y "segregación superior", para los inmigrantes de mayor renta y mejor localización.

En este contexto, la ciudad funcionaría mediante una estratificación socioeconómica de su población que, a criterio de Mera (2011), produce una diferenciación espacial y una inserción estratificada. Para Borsdorf et al. (2008), esta diferenciación por clases sociales en la ocupación del territorio da paso a la conformación de un archipiélago urbano, caracterizado por la fragmentación y la meso y micro segregación. 


\section{*.*vis revistainvi}

\section{Conclusiones}

La localización residencial en los barrios de estudio se define en función de procesos socioeconómicos, migratorios y espaciales que dan lugar a que la población inmigrante fluctúe entre la integración y la exclusión socioespacial o, bajo lo que Wormald (2007) define como, formas de integración precaria. Pero las estrategias de localización están también determinadas por condiciones estructurales del país y la ciudad de acogida, por lo que no obedecen a patrones culturales de funcionamiento.

Bajo este esquema, el acceso a la vivienda difiere en términos de ubicación espacial, condiciones de habitabilidad y nivel de apertura en el espacio de acogida, bajo una lógica en la que las características de la población definen la localización residencial en cada barrio e incluso al interior de este. Se manifiesta, entonces, la definición de escalas de acceso o restricción a ciertos espacios bajo lógicas de segregación y auto-segregación difusas que desestiman la idea de que los individuos cuentan con la posibilidad de decidir libremente sobre sus prácticas habitacionales y dan cuenta de que la inserción residencial inmigrante está estrechamente vinculada con el tema de clase.

En este contexto, la segregación residencial configura el espacio como un espejo revelador tanto de las diferencias sociales como de las prácticas urbanas neoliberales, en base a una correlación entre diferenciación social y espacial, lo que facilita la perpetuación de la estratificación, la desigualdad y la marginación de la población de condiciones socioeconómicas y migratorias determinadas.

Pero también se pone en discusión la auto-segregación residencial que, aunque fundamentado en la libre elección, de todos modos se subordina a formas de exclusión social impuestas en base a fronteras tanto concretas como simbólicas. Considerar a La Florida como un enclave étnico expresión de la libre elección residencial nos lleva a disociar el estatus económico de las características sociales y la nacionalidad; esto implicaría ignorar el hecho de que, históricamente, quienes han contado con la capacidad financiera y simbólica de elegir su localización residencial, bajo regímenes de tenencia y lógicas de estratificación urbana, han sido las clases sociales dominantes.

Las lógicas y dinámicas del asentamiento residencial inmigrante constituyen procesos estructurales anclados en la base del sistema, que dan lugar a la segmentación social del espacio. De allí que los procesos de segregación residencial explican no sólo los problemas vinculados con el tema de la vivienda, sino que parten fundamentalmente de problemas sociales estructurales que enfrentan los grupos históricamente excluidos, en situación de vulnerabilidad, o de minorías poblacionales como el caso de los inmigrantes provenientes de países en vías de desarrollo. 
En consecuencia, la localización residencial en condiciones de segregación se adscribe a la escala del funcionamiento de un sistema económico capitalista y de producción de ciudades bajo un modelo neoliberal. Como resultado, la organización y disposición del suelo en lo urbano está ligado a dinámicas de vivienda y prácticas habitacionales que potencian la producción de una estructura socioespacial desigual, que al vincularse con las condiciones socioeconómicas y migratorias de la población en situación de movilidad, fundamentan una lógica que, según Appadurai (2001), define quién es quién y quién puede tener acceso a qué.

\section{Referencias bibliográficas}

Abramo, P. (2010). El orden residencial en la sintesis espacial neoclásica. Universidad Externado de Colombia.

Abramo, P. (2012). La ciudad informal com-fusa: El mercado y la producción de la territorialidad urbana popular. En C. Salazar (Coord.), Irregular. Suelo y mercado en América Latina (pp. 85-124). El Colegio de México.

Anderson, K. (1987). The idea of Chinatown: The power of place and institutional practice in the making of a racial category. Annals of the Association of American Geographers, 77(4), 580-598. https://doi.org/10.1111/j.1467-8306.1987.tb00182.x

Appadurai, A. (2001). La modernidad desbordada. Dimensiones culturales de la globalización. Fondo de Cultura Económica.

Arbaci, S. (2008). Hacia la construcción de un discurso sobre la inmigración en las ciudades del sur de Europa. ACE: Arquitectura, Ciudad y Entorno, 3(8), 11-38. http://dx.doi.org/10.5821/ace.v3i8.2455

Arias, G., Moreno, R., y Núñez, D. (2010). Inmigración latinoamericana en Chile: analizando perfiles y patrones de localización de la comunidad peruana en el Área Metropolitana de Santiago. Tiempo y Espacio, (25).
Bayona, J. (2007). La segregación residencial de la población extranjera en Barcelona: ¿una segregación fragmentada? Scripta Nova, 11(229-255).

Blanc, M. (1988). Noiriel Gérard, Le creuset français. Histoire de l'immigration, XIX-XXe siècles. Revue Française de Sociologie, 31(3), 501-504. https://doi. org/10.2307/3322296

Boal, F. (1976). Ethnic residential segregation. Wiley.

Bolt, G., Burgers, J., y Van Kempen, R. (1998). On the social significance of spatial location; spatial segregation and social inclusion. Netherlands Journal of Housing and the Built Environment, 13(83). https://doi. org/10.1007/bf02496935

Bolt, G., Hooimeijer, P., y Van Kempen, R. (2002). Ethnic segregation in the Netherlands: new patterns, new policies? Utrecht University.

Bolt, G., Phillips, D., y Van Kempen, R. (2010). Housing policy, (de)segregation and social mixing: An international perspective. Housing Studies, 25(2), 129-135. https://doi.org/10.1080/02673030903564838

Borjas, G. (1998). To ghetto or not to ghetto: Ethnicity and residential segregation. Journal of Urban 
Economics, 44(2), 228-253. https://doi.org/10.1006/ juec.1997.2068

Borsdorf, A., Sánchez, R., y Marchant, C. (2008). Aprendiendo de los errores. La urgencia de cambios a la política nacional de vivienda. Scripta Nova, 270(51).

Brenes Camacho, G. (2003). Segregación residencial de los inmigrantes nicaragüenses en Costa Rica en 2000. Población y Salud en Mesoamérica, 1(1).

Briceño León, R. (2008). Libertad para alquilar. El mercado informal de vivienda en Caracas. Territorios, (18-19).

Camagni, R. (2005). Economía urbana. Antonio Bosch Editores.

Carrión, F. y Erazo, J. (2012). La forma urbana de Quito: una historia de centros y periferias. Bulletin de l'Institut Français d'Etudes Andines, 41(3), 503-522. https:// doi.org/10.4000/bifea.361

Colectivo IOE. (2004). Inmigración y vivienda en España. Ministerio de Trabajo y Asuntos Sociales.

Contreras, Y. (2016). Los precarios urbanos: accediendo al mercado de la vivienda informal en el alquiler y validando la tesis del mosaico socio-espacial. En P. Abramo, M. Rodríguez y J. Erazo (Coords.). Ciudades populares en disputa (pp. 421-444). Abya-Yala.

Domínguez, J., Parreño, J., y Díaz, R. (2010). Inmigración y ciudad en España: Integración versus segregación socio-territoriales. Scripta Nova, 15(331).

Echazarra, A. (2010). Segregación residencial de los inmigrantes en el área Metropolitana de Madrid. Revista Internacional de Sociología (RIS), 68(1), 165-197. https://doi.org/10.3989/ris.2007.11.12

Escaffre, F. (2018). Periferias urbanas y gobernanza urbana. [Material docente inédito].

Facultad Latinoamericana de Ciencias Sociales. (2018). Mapeo de vivienda migrante en el DMQ. [Material inédito].
Florida, R. (2010). La clase creativa: la transformación de la cultura del trabajo y el ocio en el siglo XXI. Espasa.

Fujita, M. (1989). Urban economic theory. Cambridge University Press.

Fullaondo, A., Moreno Márquez, G, y Martín Herrero, M. J. (2013). Inmigración y vivienda en tiempos de crisis: Características habitacionales y acceso a la vivienda pública [presentación]. IX Congreso Español de Sociología, España.

Galster, G., Metzger, K., y Waite, R. (1999). Neighborhood opportunity structures and immigrants' socioeconomic advancement. Journal of Housing Research, 10(1), 95-127. https://doi.org/10.1080/10835547.1999.1209 1945

García-Palomares, J. (2011). Evolución reciente y pautas de distribución espacial de las migraciones internas de inmigrantes. Scripta Nova, 15(384).

Gómez, P. y Sánchez, D. (2016). Concentración, dispersión y características sociodemográficas en la incorporación espacial de la migración peruana en la Ciudad de Córdoba, Argentina. Población y Salud en Mesoamérica, 14(1), 108-131. https://doi.org/10.15517/ psm.vl4il.25304

Harvey, D. y Chatterjee, L. (1974). Absolute rent and the structuring of space by governmental and financial institutions. Antipode, 6(1), 22-36. https://doi.org/10.1111/j.1467-8330.1974.tb00580.x

Herrera, G., Moncayo, M., y Escobar, A. (2012). Perfil migratorio del Ecuador 2011. OIM.

Instituto Nacional de Estadísticas y Censos. (2019). Entradas y salidas internacionales.

Instituto Nacional de Estadísticas y Censos. (2020). Indicadores de pobreza y desigualdad. Pobreza por necesidades básicas insatisfechas (NBI). 
Jaramillo, S. (2008). Hacia una teoría de la renta del suelo urbano. Universidad de los Andes.

Kleidermacher, G. (2017). Estrategias de inserción y circulación de migrantes senegaleses recientes en la Ciudad Autónoma de Buenos Aires. Civitas, 17(2), 251-267. https://doi.org/10.15448/1984-7289.2017.2.25306

Logan, J., Zhang, W., y Alba, R. (2002). Inmigrant enclaves and ethnic communities in New York and Los Angeles. American Sociological Review, 67(2), 299-322. https://doi.org/10.2307/3088897

Marengo, C. (2004). Una aproximación a la segregación residencial, como punto de partida en la formulación de políticas. Revista INVI, 19(50), 165-181.

Martínez del Olmo, A. y Leal Maldonado, J. (2008). La segregación residencial, un indicador espacial confuso en la representación de la problemática residencial de los inmigrantes económicos. ACE: Architecture, City and Environment, (8), 53-64.https://doi.org/10.5821/ ace.v3i8.2457

Martori, J. y Hoberg, K. (2006). Población inmigrante y espacio urbano. Indicadores de segregación y pautas de localización. EURE, 32(97), 49-62. https://doi. org/10.4067/S0250-71612006000300004

Massey, D., Arango, J., Hugo, G., Koucouci, A., Pellegrino, A., y Taylor, E. (1998). Worlds in motion: International migration at the end of the millenium. Oxford University Press.

Massey, D. y Denton, N. (1993). American Apartheid. Harvard University Press.

Mera, G. (2011). Pensar las categorías, pensar al Estado. El concepto de segregación espacial de los inmigrantes en los estudios migratorios. Instituto de Investigaciones Gino Germani, UBA.

Murdie, R. y Borgegard, L. (1998). Immigration, spatial segregation and housing segmentation of immigrants in Metropolitan Stockholm, 196095. Urban Studies, 35(10), 1869-1888. https://doi. org/10.1080/0042098984196

Musterd, S. (2010). Segregation and integration: A contested relationship. Journal of Ethnic and Migration Studies, 29(4), 623-641. https://doi.org/10.1080/136918 3032000123422

Musterd, S. (2011). The impact of immigrants' segregation and concentration on social integration in selected European contexts. Documents d'Anàlisi Geogràfica, 57(3), 359-380. https://doi.org/10.5565/rev/dag.226

Oliveira, G. d., Hurtado, C., e Iglesias, R., (2016). Cambios en la localización residencial de la inmigración en el área metropolitana de Sevilla. Anales de Geografía de la Universidad Complutense, 37(1), 107-133.

Parias, A. (2008). El mercado de arrendamiento en los barrios informales en Bogotá, un mercado estructural. Territorios, (18-19), 75-101.

Peach, C. (2010). The meaning of segregation. Planning Practice \& Research, 11(2), 137-150. https://doi. org/10.1080/02697459650036297

Pedreño, A. (1999). Construyendo la huerta de Europa: trabajadores sin ciudadanía y nómadas permanentes en la agricultura murciana. Migraciones, (5), 87-120.

Portes, A. (1995). Economic sociology and the sociology of immigration: A conceptual overview. Russell Sage Foundation

Portes, A. y Zhou, M. (1996) Self-employment and the earnings of immigrants, American Sociological Review, 61(2), 219-230. https://doi.org/10.2307/2096332

Rodríguez, M. (2017). La contribución de las políticas públicas y la normativa para el control de la especulación del suelo. IAEN.

Sabatini, F. (2006). La segregación social del espacio en las ciudades de América Latina. BID 
Sabatini, F. y Brain, I. (2008). La segregación, los guetos y la integración social urbana: mitos y claves. Eure, 34(103), 5-26. https://doi.org/10.4067/ $\underline{\text { S0250-71612008000300001 }}$

Sassone, S. y Mera, C. (2006). Barrios de migrantes en Buenos Aires: Identidad, cultura y cohesión socioterritorial [la palabra]. XXVI Congreso de la Asociación Latinoamericana de Sociología, Guadalajara, México.

Schelling, T. (1978). Micromotives and macrobehavior. Norton.

Secretaría de Territorio. (2017). Plan Especial de Recuperamiento Urbano del Sector La Floresta. Alcaldía del Distrito Metropolitano.

Simon, P. (1998). Mobilité résidentielle et milieu de vie des inmigrés. Presses Universitaires de Lyon.

Sistema Continuo de Reportes sobre Migración Internacional en las Américas. (2015). Migraciones internacionales en las Américas. OEA.

Smolka, M. (2005). El funcionamiento de los mercados del suelo en América latina. Lincoln Institute of Land Policy/ INVICO.

Strohmayer, H., Carrasquilla, C., Castellanos, M., García, I., y Pedreño, A. (2005). Inmigración y diferenciación socioespacial. España: Universidad de Murcia.

Torres, F. Carrasquilla, C. Gadea, E., y Meier, S. (2007). Los nuevos vecinos de la comunidad del Sureste. Servicio de Publicaciones de la Universidad de Murcia.

Torres, F. (2009). La inserción residencial de los inmigrantes en la costa mediterránea española. 1998-2007. Co-presencia residencial, segregación y contexto local. Áreas. Revista Internacional de Ciencias Sociales, (28), 73-87.
Wacquant, L. (1996). The rise of advanced marginality: Notes on its nature and implications. Acta Sociológica, 39(2), 121-139.

Wormald, G. (2007). ¿Cómo debe entenderse la integración social en la ciudad? [presentación]. ProUrbana.

Tuan, Y. (2007). Topofilia. Un estudio de las percepciones, actitudes y valores sobre el entorno. Melusina. 


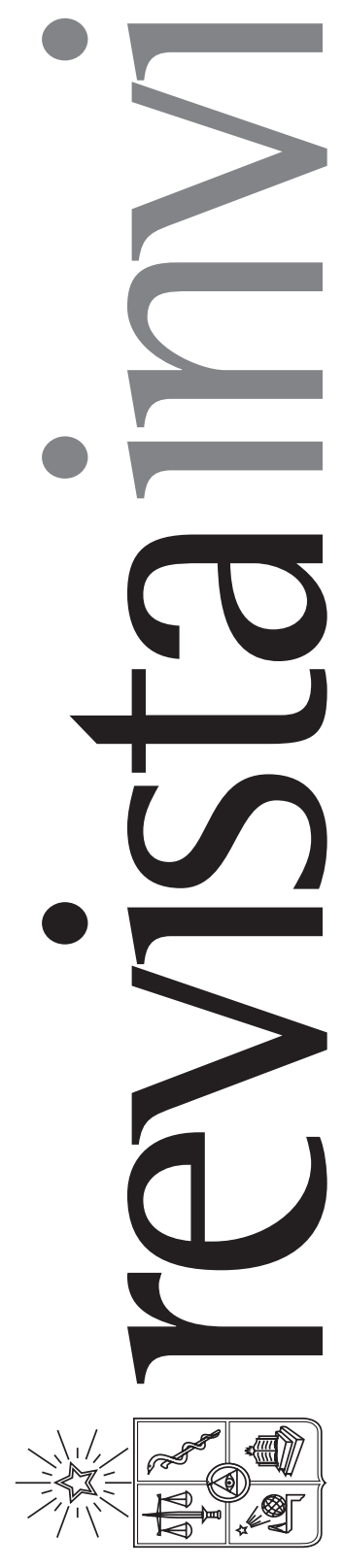

Revista INVI es una publicación periódica, editada por el Instituto de la Vivienda de la Facultad de Arquitectura y Urbanismo de la Universidad de Chile, creada en 1986 con el nombre de Boletín INVI. Es una revista académica con cobertura internacional que difunde los avances en el conocimiento sobre la vivienda, el hábitat residencial, los modos de vida y los estudios territoriales. Revista INVI publica contribuciones originales en español, inglés y portugués, privilegiando aquellas que proponen enfoques inter y multidisciplinares y que son resultado de investigaciones con financiamiento y patrocinio institucional. Se busca, con ello, contribuir al desarrollo del conocimiento científico sobre la vivienda, el hábitat y el territorio y aportar al debate público con publicaciones del más alto nivel académico.

Directora: Dra. Mariela Gaete Reyes, Universidad de Chile, Chile Editor: Dr. Luis Campos Medina, Universidad de Chile, Chile.

Editores asociados: Dr. Gabriel Felmer, Universidad de Chile, Chile.

Dr. Walter Imilan, Universidad de Chile, Chile.

Coordinadora editorial: Sandra Rivera, Universidad de Chile, Chile.

Asistente editorial: Katia Venegas, Universidad de Chile, Chile.

\section{COMITÉ EDITORIAL:}

Dr. Victor Delgadillo, Universidad Autónoma de la Ciudad de México, México.

Dra. María Mercedes Di Virgilio, CONICET/ IIGG, Universidad de Buenos Aires, Argentina. Dra. Irene Molina, Uppsala Universitet, Suecia.

Dr. Gonzalo Lautaro Ojeda Ledesma, Universidad de Valparaíso, Chile.

Dra. Suzana Pasternak, Universidade de São Paulo, Brasil.

Dr. Javier Ruiz Sánchez, Universidad Politécnica de Madrid, España.

Dra. Elke Schlack Fuhrmann, Pontificia Universidad Católica de Chile, Chile.

Dr. Carlos Alberto Torres Tovar, Universidad Nacional de Colombia, Colombia.

Sitio web: http://www.revistainvi.uchile.cl/

Correo electrónico: revistainvi@uchilefau.cl Licencia de este artículo: Creative Commons Atribución-Compartirlgual 4.0 Internacional (CC BY-SA 4.0) 